\title{
A Cross-Sectional Analysis to Evaluate Knowledge, Attitude And Practices Among Pregnant Women During COVID-19 Pandemic
}

\author{
Tarang P. Kaur ${ }^{1}$ - Anubhuti Rana ${ }^{1}$ - Vanamail Perumal ${ }^{1} \cdot$ Aparna Sharma $^{1} \cdot$ Vatsla Dadhwal $^{1} \cdot$ Vidushi Kulshrestha $^{1}$. \\ Seema Singhal ${ }^{1}$. Jyoti Meena ${ }^{1} \cdot$ Sunesh Kumar ${ }^{1} \cdot$ Neerja Bhatla ${ }^{1}$
}

Received: 14 July 2021 / Accepted: 22 August 2021 / Published online: 4 September 2021

(c) Federation of Obstetric \& Gynecological Societies of India 2021

\begin{abstract}
Objective To assess knowledge, attitude and practices (KAP) towards COVID-19 among pregnant women at a tertiary care hospital.

Methods This was a questionnaire-based cross-sectional analysis pertaining to COVID-19 which was conducted at a tertiary care obstetric facility in India among 200 consecutive consenting pregnant women. They were assessed for demographic details and KAP score (knowledge—17 questions, attitude — 9 questions and practice-8 questions). Analysis of data was done using Statistical Package for the Social Sciences (SPSS) version 25.0.

Results The participants had adequate mean knowledge score $( \pm$ SD) of $22.5( \pm 3.5)$ were following good practices [mean score $( \pm$ SD $)=15.5( \pm 2.6)]$ and showed positive attitude for preventive measures against COVID-19 $[n(\%)=194(96 \%)]$. Low knowledge score ( $p$-value 0.030 ) was seen in non-health care workers.

Conclusion This study demonstrated that majority of the pregnant women had satisfactory knowledge, positive attitude and were following practices in right manner regarding COVID-19 but continued efforts for generating awareness were warranted.
\end{abstract}

Tarang P. Kaur and Anubhuti Rana contributed equally to the study and share the first authorship

Tarang P. Kaur, MS Obstetrics and Gynaecology, Senior Resident, Department of Obstetrics and Gynaecology, All India Institute of Medical Sciences, New Delhi; Anubhuti Rana, MS Obstetrics and Gynaecology, Assistant Professor, Department of Obstetrics and Gynaecology, All India Institute of Medical Sciences, New Delhi; Vanamail Perumal, Additional Professor of Statistics and Demography, Department of Obstetrics and Gynaecology, All India Institute of Medical Sciences, New Delhi; Aparna Sharma, MD Obstetrics and Gynaecology, Additional Professor, Department of Obstetrics and Gynaecology, All India Institute of Medical Sciences, New Delhi; Vatsla Dadhwal, MD Obstetrics and Gynaecology, Professor, Department of Obstetrics and Gynaecology, All India Institute of Medical Sciences, New Delhi; Vidushi Kulshrestha, MS Obstetrics and Gynaecology, Associate Professor, Department of Obstetrics and Gynaecology, All India Institute of Medical Sciences, New Delhi; Seema Singhal, MD Obstetrics and Gynaecology, Associate Professor, Department of Obstetrics and Gynaecology, All India Institute of Medical Sciences, New Delhi; Jyoti Meena, MS Obstetrics and Gynaecology, Associate Professor, Department of Obstetrics and Gynaecology, All India Institute of Medical Sciences, New Delhi; Sunesh Kumar, MD Obstetrics and Gynaecology, Professor, Department of Obstetrics and Gynaecology, All India Institute of Medical Sciences, New Delhi; Neerja Bhatla, MD Obstetrics and Gynaecology, Professor, Department of Obstetrics and Gynaecology, All India Institute of Medical Sciences, New Delhi

Extended author information available on the last page of the article 
As India is battling the second COVID-19 wave and in the absence of definitive cure, strengthening of health policies directed at pregnant women should be prioritized with special focus on significant gaps in KAP.

Keywords COVID-19 $\cdot$ Pregnant $\cdot$ Knowledge $\cdot$ Attitude $\cdot$ Practice

\section{Introduction}

The infectious coronavirus disease (COVID-19) has led to a global pandemic making it one of the biggest public health emergencies for mankind $[1,2]$. The only effective approach in cutting down the spread of infection is to create public awareness and taking precautions as no definitive treatment is proven yet [3]. Government of India (GOI) has taken necessary steps to disseminate the required information among citizens by engaging in media campaigns and issuing advisories about the novel coronavirus, its mode of transmission and preventive measures to the general public. The Health Ministry via Department of Telecommunications has reached people across the country by directing all known telecom companies to include a 30-s COVID-19 prevention caller tune to their networks. The GOI has left no stone unturned to educate people about best practices and spreading pertinent advisories regarding control of spread of COVID-19 and has also launched the Aarogya Setu mobile application in this regard. [4].

People must adhere to preventive behaviour, which is mostly influenced by their knowledge, attitudes and practices (KAP), in order to curtail spread of infection [5]. It is also known that knowledge and attitude of public towards infectious diseases affect their emotions and panic reactions can impede preventive attempts to control spread of infection [6]. Pregnant women form a special vulnerable group due to unique changes in pregnancy placing them at a higher risk for contracting severe infection [3]. Current awareness among pregnant women regarding COVID-19 is inadequately studied, so the aim of this analysis was to evaluate KAP of pregnant women regarding COVID-19 at a tertiary care obstetric centre in India.

\section{Material and Methods}

This was a cross-sectional analysis conducted at a tertiary hospital in India. Approval was sought from Institute Ethics Committee (Reference no.-IECPG-247/24.06.2020, RT- 32/22.07.2020). All pregnant women attending the hospital were invited to participate in the study. Women who were not willing to participate or those who were sick/ hemodynamically unstable were excluded. After obtaining informed written consent, 200 consecutive consenting pregnant women were recruited.
A questionnaire was self-constructed based on Royal College of Obstetricians and Gynaecologists (RCOG) guideline and World Health Organization (WHO) recommendations on COVID-19 in pregnancy [7, 8]. It was reviewed and verified by all the authors. The questionnaire was available in both English and Hindi language; translation in Hindi was done by a language expert. In case the woman was illiterate, she was administered the questionnaire verbally by a member of the study team.

The questionnaire comprised of two sections-demographic details and KAP. Demographic details included name, age, address, religion, education status and profession. Source of knowledge of participants on COVID-19 including mass media, family and friends or health care providers was also recorded. The KAP part of questionnaire assessed various aspects of knowledge, attitude and practices relating to COVID-19 infection.

The knowledge was evaluated through a set of 17 questions on epidemiology, transmission, clinical features, prevention, treatment available, effect of COVID-19 on mother and foetus, mode of delivery in COVID-19 mothers, feeding options for baby and different district zones based on risk profile. To investigate the degree of knowledge of each pregnant woman, a scoring system was applied. Depending on the question and response, score of 2 was given for correct response, 1 was given to a response which was correct to some extent and 0 was given to wrong response. The score ranged from 0 to 33 and sufficient knowledge was present if their score was equal to or more than the median score. Pregnant women were categorised as having inadequate knowledge if they scored less than the median.

Attitude was measured by a set of 9 questions which evaluated their behaviour towards COVID-19 disease, seriousness in following preventive measures, concerns if they contract the disease, place of delivery and quarantine and their confidence in victory in the fight against COVID-19. Practices among participants were scored using 8 questions based on adherence to preventive measures, frequency of handwashing, eating habits, behavioural changes towards family members, consumption of herbal medicines, coughing etiquettes and preferred feeding methods for the baby. Total practice score ranged from 2 to 23 . Furthermore, 3 more practice related questions were asked. One was related to change in frequency of sexual intercourse since onset of pandemic and other was most common daily activity related to increased frequency of handwashing during pandemic. The third question was a hypothetical situation of 
first trimester during pandemic and their decision regarding continuation or termination of pregnancy. These 3 questions were not scored as there was no particular correct response to these practices. Respondents were classified as following good practices if their score was equal to or more than the median value. Participants scoring less than the median score were categorised as those with poor practices.

Data were compiled using the excel spreadsheet. Statistical analyses were carried out using Statistical Package for the Social Sciences (SPSS) for windows version 25.0 (SPSS Inc., Chicago, IL, USA). Qualitative variables were presented as numbers or percentages. Frequency data across categories were compared either by Fisher's exact test or Pearson's Chi-square test as appropriate. Mean values of normally distributed data (tested by Kolmogorov-Smirnov) were tested by one-way ANOVA/students $t$-independent test as appropriate. We used either Mann-Whitney $U$ test or Kruskal-Wallis test for comparison of median values of skewed as appropriate. Statistical significance was considered at $p$-value $\leq 0.05$ for all statistical tests.

\section{Results}

A total of 200 pregnant women participated in the study. Baseline information of study participants is depicted in Table 1. For each question on knowledge, the distribution of responses from participants was investigated (Table 2). Overall, the respondents had adequate mean knowledge score $( \pm \mathrm{SD})$ of $22.5( \pm 3.5)$. The median knowledge score was 21 with $60 \%$ respondents having adequate knowledge (score $\geq 21$ ) regarding COVID-19.

The attitude of pregnant women towards COVID-19 was studied through various questions listed in Table 3 . There was universal agreement among pregnant women (100\%) regarding delivery at hospital if they contracted COVID-19.

Response to each question on practices towards COVID19 is presented in Table 4. Among the participants, increase in sexual intercourse frequency was seen in $22 \%$ (44), decrease in $50 \%$ (100) and no change in $28 \%$ (56) which could be due to the fear of contracting COVID-19 from their partners and thus affecting the course of pregnancy. When given the option of either continuing with pregnancy or terminating it in first trimester as a hypothetical situation, majority $(91 \%)$ of the participants opted for continuation of pregnancy. Of these, $27.5 \%$ participants were confident regarding practicing preventive measures properly, 29\% believed that they would take available treatment and get cured of COVID-19, 15\% believed that neither she nor her baby would contract COVID-19, $14.5 \%$ wanted that baby as they feared infertility in future and $5.5 \%$ regarded baby as God's gift. Around $9 \%$ of pregnant mothers wanted to abort
Table 1 Baseline characteristics of study participants

\begin{tabular}{|c|c|}
\hline Parameter & Total number $=200$ \\
\hline Age (Years) $($ Mean \pm S.D) & $28.6 \pm 3.9$ \\
\hline Range (Years) & $19-38$ \\
\hline \multicolumn{2}{|l|}{ Religion $n(\%)$} \\
\hline Hindu & $173(86.5)$ \\
\hline Muslim & $19(9.5)$ \\
\hline Sikh & $1(0.5)$ \\
\hline Christian & $7(3.5)$ \\
\hline \multicolumn{2}{|l|}{ Area of living $n(\%)$} \\
\hline Rural & $32(16.0)$ \\
\hline Suburban & $22(11.0)$ \\
\hline Urban & $146(73.0)$ \\
\hline \multicolumn{2}{|c|}{ Distribution of subjects by COVID status of current residence $n(\%)$} \\
\hline Hotspot & $20(10)$ \\
\hline Non-hotspot & $180(90)$ \\
\hline \multicolumn{2}{|l|}{ Education level $n(\%)$} \\
\hline Primary education and below & $32(16)$ \\
\hline Secondary education & $90(45)$ \\
\hline Graduation and higher & $78(39)$ \\
\hline \multicolumn{2}{|l|}{ Occupation n (\%) } \\
\hline Health care related & $27(13.5)$ \\
\hline Non-health care related & $173(86.5)$ \\
\hline \multicolumn{2}{|l|}{ Source of information $n(\%)^{a}$} \\
\hline Mass media- specify & $184(92)$ \\
\hline Family and friends & $40(20)$ \\
\hline Healthcare providers & 34 (17) \\
\hline
\end{tabular}

a $\%$ values exceeded 100 due to multiple responses

the baby in view of COVID-19 pandemic as they feared the effect on foetus as no cure was available.

Baseline characteristics of study participants were compared with mean knowledge and practice score. Health care workers had significantly increased mean knowledge score ( $P$-value 0.030$)$ when compared to non-health care workers. However, their mean practice scores revealed no statistically significant difference (Table 5).

Various study variables were correlated with different domains of knowledge and practices as shown in Table 6 . Significant positive correlation $(r=0.150)$ was seen between knowledge about type of disease and frequency of handwashing $(p$-value $=0.034)$ and also with preventive measures $(r=0.256 ; p$-value $<0.001)$ being practiced by participants. Those women who were aware about the symptoms suggestive of COVID-19 had positive correlation $(r=0.205)$ with preventive practices ( $p$-value 0.004 ). Those who were aware about prevalence of COVID-19 were found to have significantly increased frequency of handwashing ( $p$-value 0.009). Significant positive correlation $(r=0.141)$ was seen between knowledge about the risk of COVID-19 in pregnancy and preventive use of face masks ( $p$-value 0.046). Significant 
Table 2 Knowledge regarding COVID-19

\begin{tabular}{|c|c|c|c|c|}
\hline \multicolumn{2}{|c|}{ Question } & \multirow{2}{*}{$\begin{array}{l}\text { Response } \\
\text { Pandemic }\end{array}$} & \multirow{2}{*}{$\begin{array}{l}\text { Score } \\
1\end{array}$} & \multirow{2}{*}{$\begin{array}{l}n(\%) \\
150(75)\end{array}$} \\
\hline $\mathrm{K} 1$ & What is the current stage of spread of COVID-19? & & & \\
\hline & & Others (outbreak, epidemic) & 0 & $50(25)$ \\
\hline & Mean score $\pm \mathrm{SD}$, (range) & & $0.8 \pm 0.4,(0-1)$ & \\
\hline \multirow[t]{4}{*}{ K2 } & \multirow[t]{3}{*}{ What type of disease is COVID-19? } & - Communicable & 2 & $150(75)$ \\
\hline & & - Both communicable and non-communicable & 1 & $32(16)$ \\
\hline & & - Non-communicable/not answered & 0 & $18(9)$ \\
\hline & Mean score $\pm \mathrm{SD}$, (range) & & $1.7 \pm 0.6,(0-2)$ & \\
\hline \multirow[t]{3}{*}{ K3 } & \multirow{2}{*}{$\begin{array}{l}\text { Which group is at the highest risk of contracting } \\
\text { severe form of COVID-19? }\end{array}$} & Adults with comorbidities & 1 & $102(51)$ \\
\hline & & $\begin{array}{l}\text { Others (adults without comorbidities, all age groups, } \\
\text { pregnant women) }\end{array}$ & 0 & $98(49)$ \\
\hline & Mean score $\pm \mathrm{SD}$, (range) & & $0.5 \pm 0.51,(0-1)$ & \\
\hline \multirow[t]{5}{*}{ K4 } & \multirow{4}{*}{$\begin{array}{l}\text { Which of the following are symptoms suggestive of } \\
\text { COVID-19? }\end{array}$} & Fever & 1 & $196(98)$ \\
\hline & & Cough & 1 & $196(98)$ \\
\hline & & Breathlessness & 1 & $192(96)$ \\
\hline & & Myalgia/weakness & 1 & $154(77)$ \\
\hline & Mean score $\pm \mathrm{SD}$, (range) & & $3.7 \pm 0.6,(1-4)$ & \\
\hline \multirow[t]{3}{*}{ K5 } & \multirow[t]{2}{*}{ How can COVID-19 be transmitted? } & Respiratory droplets & 1 & $192(96)$ \\
\hline & & Others (flies, mosquitoes, meat products) & 0 & $8(4)$ \\
\hline & Mean score $\pm \mathrm{SD}$, (range) & & $1.0 \pm 0.2,(0-1)$ & \\
\hline \multirow[t]{5}{*}{ K6 } & \multirow{4}{*}{$\begin{array}{l}\text { Which of the following are preventive measures for } \\
\text { COVID-19? }\end{array}$} & Social distancing & 1 & $196(98)$ \\
\hline & & Hand hygiene & 1 & $194(97)$ \\
\hline & & Wearing masks & 1 & $194(97)$ \\
\hline & & Avoiding crowded places & 1 & $196(98)$ \\
\hline & Mean score $\pm \mathrm{SD}$, (range) & & $3.9 \pm 0.5,(1-4)$ & \\
\hline \multirow[t]{3}{*}{ K7 } & \multirow{2}{*}{$\begin{array}{l}\text { What is the ideal duration of handwashing for hand } \\
\text { hygiene? }\end{array}$} & $20-30 s$ & 1 & $96(48)$ \\
\hline & & Others ( $2 \mathrm{~min}, 3 \mathrm{~min},>3 \mathrm{~min})$ & 0 & $104(52)$ \\
\hline & Mean score $\pm \mathrm{SD}$, (range) & & $0.5 \pm 0.5,(0-1)$ & \\
\hline \multirow[t]{3}{*}{ K8 } & \multirow{2}{*}{$\begin{array}{l}\text { What is the trend of prevalence of COVID-19 in } \\
\text { India? }\end{array}$} & Increasing & 1 & $150(75)$ \\
\hline & & Others (same, decreasing, do not know) & 0 & $50(25)$ \\
\hline & Mean score $\pm \mathrm{SD}$, (range) & & $0.7 \pm 0.4,(0-1)$ & \\
\hline \multirow[t]{4}{*}{ K9 } & \multirow{3}{*}{$\begin{array}{l}\text { Does COVID-19 pose additional risk of infection to } \\
\text { the pregnancy? }\end{array}$} & No & 2 & $6(3)$ \\
\hline & & Do not know & 1 & $48(24)$ \\
\hline & & Yes & 0 & $146(73)$ \\
\hline & Mean score $\pm \mathrm{SD}$, (range) & & $0.3 \pm 0.5,(0-2)$ & \\
\hline \multirow[t]{5}{*}{ K10 } & \multirow[t]{5}{*}{ If the answer to question 9 is yes, then how- } & (a) The foetus will be affected & NA & NA \\
\hline & & (b) Delivery will be complicated & & \\
\hline & & (c) Antenatal complications are associated & & \\
\hline & & (d) All of the above & & \\
\hline & & (e) More research is required & & \\
\hline \multirow[t]{6}{*}{ K11 } & \multirow{5}{*}{$\begin{array}{l}\text { What is the treatment of cure available for COVID- } \\
19 ?\end{array}$} & Vaccine & 1 & $26(13)$ \\
\hline & & Homoeopathic & 1 & $4(2)$ \\
\hline & & Allopathic & 1 & $14(7)$ \\
\hline & & No proven treatment yet & 2 & $142(71)$ \\
\hline & & Not answered & 0 & $14(7)$ \\
\hline & Mean score $\pm \mathrm{SD}$, (range) & & $1.6 \pm 0.6,(0-2)$ & \\
\hline
\end{tabular}


Table 2 (continued)

\begin{tabular}{|c|c|c|c|c|}
\hline \multicolumn{2}{|c|}{ Question } & \multirow{2}{*}{$\begin{array}{l}\text { Response } \\
\text { Hydroxychloroquine }\end{array}$} & \multirow{2}{*}{ Score } & \multirow{2}{*}{$\frac{n(\%)}{120(60)}$} \\
\hline K12 & What is the prophylactic treatment available for & & & \\
\hline & & Vaccine & 1 & $88(44)$ \\
\hline & & Lemon & 1 & $88(44)$ \\
\hline & & Ginger/garlic & 1 & $86(43)$ \\
\hline & & Not answered & 0 & 0 \\
\hline & Mean score $\pm \mathrm{SD}$, (range) & & $1.9 \pm 1.5,(0-4)$ & \\
\hline \multirow[t]{6}{*}{ K13 } & \multirow{5}{*}{$\begin{array}{l}\text { What should be the mode of delivery in COVID-19 } \\
\text { patient? }\end{array}$} & Vaginal delivery & 1 & $32(16)$ \\
\hline & & Operative vaginal delivery & 1 & $4(2)$ \\
\hline & & Caesarean section & 1 & $46(23)$ \\
\hline & & Not affected by COVID-19 status & 2 & $46(23)$ \\
\hline & & Not answered & 0 & $72(36)$ \\
\hline & Mean score $\pm \mathrm{SD}$, (range) & & $0.9 \pm 0.7,(0-2)$ & \\
\hline \multirow[t]{5}{*}{ K14 } & \multirow{4}{*}{$\begin{array}{l}\text { What are the feeding options for the baby born to } \\
\text { COVID-19 mother? }{ }^{\text {a }}\end{array}$} & Breastfeeding & 1 & $36(18)$ \\
\hline & & Expressed breast milk & 1 & $50(25)$ \\
\hline & & Formula-feed & 1 & $94(47)$ \\
\hline & & Not answered & 0 & $40(20)$ \\
\hline & Mean score $\pm \mathrm{SD}$, (range) & & $0.9 \pm 0.6,(0-3)$ & \\
\hline \multirow[t]{4}{*}{ K15 } & \multirow{3}{*}{$\begin{array}{l}\text { What precautions should you ensure if you are tested } \\
\text { COVID-19 positive, and you are with the baby? }{ }^{\text {a }}\end{array}$} & Hand hygiene & 1 & $194(97)$ \\
\hline & & Wear mask & 1 & $196(98)$ \\
\hline & & $\begin{array}{l}\text { Disinfecting/cleaning surfaces with which you have } \\
\text { been contacting with }\end{array}$ & 1 & $182(91)$ \\
\hline & Mean score $\pm \mathrm{SD}$, (range) & & $2.9 \pm 0.4,(0-3)$ & \\
\hline \multirow[t]{3}{*}{ K16 } & \multirow{2}{*}{$\begin{array}{l}\text { If a pregnant female has been close contact with } \\
\text { someone infected with the COVID-19 virus, what } \\
\text { should be the period of isolation for observation of } \\
\text { symptoms? }\end{array}$} & 14 days & 1 & $154(77)$ \\
\hline & & Others ( 7 days, $>14$ days, do not know) & 0 & $46(23)$ \\
\hline & Mean score $\pm \mathrm{SD}$, (range) & & $0.8 \pm 0.4,(0-1)$ & \\
\hline \multirow[t]{4}{*}{ K17 } & \multirow{2}{*}{$\begin{array}{l}\text { If you are residing in the red zone, what is your risk } \\
\text { of having COVID-19? }\end{array}$} & Higher than the green zone & 1 & $106(53)$ \\
\hline & & $\begin{array}{l}\text { Others (same as green zone, higher than green zone, } \\
\text { lower than orange zone) }\end{array}$ & 0 & $94(47)$ \\
\hline & Mean score $\pm \mathrm{SD}$, (range) & & $0.5 \pm 0.50,(0-1)$ & \\
\hline & Overall mean knowledge score $\pm \mathrm{SD}$, (range) & & $22.6 \pm 3.5,(10-29)$ & \\
\hline
\end{tabular}

${ }^{\text {a }}$ Due to multiple responses, more than 100 per cent is possible

negative correlation ( $r=-0.162$ ) was found between knowledge about preventive measures for COVID-19 and use of herbal products and traditional medicines ( $p$-value 0.022 ).

\section{Discussion}

This study was conducted with the aim of providing an insight into the knowledge, attitude and practices of pregnant women regarding COVID-19 infection. Pregnant women form a unique vulnerable group due to the immunological suppression during pregnancy and measures should be taken to prevent COVID-19 infection in this subgroup. This is crucial particularly in developing nations like India where the health infrastructure is not as strong as in developed countries.

Respondents had an overall correct knowledge rate of $68.5 \%(22.6 / 33 * 100)$, demonstrating that majority of pregnant women were knowledgeable about coronavirus but previous study in China among general population showed greater correct knowledge rate (90\%) [9]. Overall, mean knowledge score (22.5) of the participants was adequate which is similar to knowledge level among pregnant women in previous study [10]. The adequate knowledge could be attributed to robust efforts by GOI in spreading information and increasing awareness since the beginning of pandemic. Therefore, it is not surprising that mass media (television, radio and internet) were the primary sources of information about COVID-19 for majority of the study participants 
Table 3 Attitude towards COVID-19

\begin{tabular}{|c|c|c|c|}
\hline \multicolumn{2}{|c|}{ Question } & \multirow{2}{*}{$\begin{array}{l}\text { Response } \\
\text { Yes }\end{array}$} & \multirow{2}{*}{$\frac{n(\%)}{78(39)}$} \\
\hline A1 & Do you think you can have COVID-19? & & \\
\hline & & No & $66(33)$ \\
\hline & & Do not know & $56(28)$ \\
\hline \multirow[t]{3}{*}{$\mathrm{A} 2$} & Do you think your baby can be affected? & Yes & $68(34)$ \\
\hline & & No & $70(35)$ \\
\hline & & Do not know & $62(31)$ \\
\hline \multirow[t]{4}{*}{ A3 } & If you develop symptoms suggestive of COVID-19, whom would you & Health personnel & $114(57)$ \\
\hline & communicate about it first? & Parents & $16(8)$ \\
\hline & & Husband & $70(35)$ \\
\hline & & Nobody & $0(0)$ \\
\hline \multirow[t]{3}{*}{ A4 } & What will you do if you suspect that you have COVID-19? & Visit health care facility & $172(86)$ \\
\hline & & Visit traditional/ local healer & $28(14)$ \\
\hline & & Do not believe in treatment & $0(0)$ \\
\hline \multirow[t]{5}{*}{ A5 } & What concerns you the most if you are diagnosed with COVID-19? & Fear of transmitting it to baby/family members & $138(69)$ \\
\hline & & Social stigma & $2(1)$ \\
\hline & & Cost of treatment & $0(0)$ \\
\hline & & Fear of death & $18(9)$ \\
\hline & & I am confident that it will get cured & $42(21)$ \\
\hline \multirow[t]{5}{*}{ A6 } & On a scale of $1-5$, how seriously one should follow preventive steps? & 1 & $4(2)$ \\
\hline & & 2 & $0(0)$ \\
\hline & 1 -minimum, 5-maximum & 3 & $4(2)$ \\
\hline & & 4 & $14(7)$ \\
\hline & & 5 & $178(89)$ \\
\hline \multirow[t]{3}{*}{ A7 } & Where should the pregnant females with COVID-19 get delivered? & (a) Home & $0(0)$ \\
\hline & & (b) Hospital & $100(100)$ \\
\hline & & (c) Does not matter & $0(0)$ \\
\hline \multirow[t]{3}{*}{ A8 } & Suppose you test COVID-19 positive and are asymptomatic, where & Home & $88(44)$ \\
\hline & would you opt to get quarantined? & Hospital & $92(46)$ \\
\hline & & Anywhere & $20(10)$ \\
\hline \multirow[t]{3}{*}{ A9 } & Do you think that India can win the battle against COVID-19? & Yes & $172(86)$ \\
\hline & & No & $4(2)$ \\
\hline & & Do not know & $24(12)$ \\
\hline
\end{tabular}

(92\%) which is similar to the study results among pregnant women in a low-resource African setting [11]. Significant predictor of knowledge was occupation $(p$-value $=0.030)$ with higher scores observed in health care workers as expected. There was no significant correlation of knowledge score with education, religion or area of distribution by COVID-19 status which is in contrast to previous studies $[9,10]$. Commonly known COVID-19 related symptoms were fever $(98 \%)$, cough $(98 \%)$ and breathlessness $(96 \%)$ but pregnant women were comparatively less aware about myalgia/weakness (77\%) which is similar to the results of study in Iran by Erfani et al. [12] and this could be possible as myalgia and weakness are considered as physiological symptoms in pregnancy.

Health crisis situation like this also demands efforts towards correcting misleading information and misguided perceptions of the general public. This study discovered various misconceptions among pregnant respondents regarding the duration of handwashing, additional risk of COVID-19 in pregnancy and feeding options for the baby. Less than half (48\%) of the participants correctly answered ideal duration of handwashing. Majority of the participants (73\%) believed that COVID-19 poses additional risk of infection to pregnancy due to effect on the foetus (17\%), antenatal complications $(9 \%)$, delivery-related complications $(3 \%)$ or all of the above $(25 \%)$ whereas $18 \%$ answered that more research was required on this topic while $28 \%$ did not answer. These concerns can lead to unnecessary apprehension among pregnant mothers as revealed by other studies [13, 14]. Majority of the pregnant mothers $(71 \%)$ were aware that there was no clinically approved treatment for COVID-19 and 13\% thought that vaccine was the available treatment of choice 
Table 4 Practice towards COVID-19

\begin{tabular}{ll}
\hline Question & Response \\
\hline P1 $\quad \begin{array}{l}\text { What precautions are you practicing in order to prevent con- } \\
\text { tracting and spreading of COVID-19? } *\end{array}$ & (a) Wearing mask \\
& (b) Avoid crowded places \\
& (c) Avoid handshaking \\
Mean score $\pm \mathrm{SD}$, (range) & (d) Washing vegetables before storing them
\end{tabular}

P2 Has there been any change in the frequency of handwashing to prevent contracting and spreading of COVID-19?
(a) Increased
(b) Decreased
(c) Same as before

\begin{tabular}{ll} 
Score & $\underline{n}(\%)$ \\
\hline 1 & $196(98)$ \\
1 & $190(95)$ \\
1 & $182(91)$ \\
1 & $164(82)$ \\
1 & $178(89)$ \\
$4.5 \pm 1.0,(1-5)$ & \\
2 & $174(87)$ \\
0 & $4(2)$ \\
1 & $22(11)$ \\
$1.9 \pm 0.40,(0-2)$ & \\
Not applicable & \\
Not applicable & $44(22)$ \\
& $100(50)$ \\
& $56(28)$ \\
Not applicable & $182(91)$ \\
& $18(9)$
\end{tabular}

COVID-19 pandemic; would you like to continue pregnancy?

Mean score $\pm \mathrm{SD}$, (range)
(a) Increased
(b) decreased
(c) Same
(a) Yes, I want to Continue pregnancy
(b) I do not want to continue pregnancy

$18(9)$

P6 Has there been any change in behaviour towards family members? *
$142(71)$
(a) Avoid hugging
$133(66.5)$
(b) Avoid kissing
$122(61)$
(c) Avoid sharing food from the same plate 1
$88(44)$
(d)Avoid sleeping together
$46(23)$
(e) No change
0

Mean score $\pm \mathrm{SD}$, (range)
(a) Always
(b) Most of the times
(c) Do not believe in it

Mean score $\pm \mathrm{SD}$, (range)

P8 Any change in eating habits to prevent contracting COVID19 ?*
(a) Eat more of lemon
(b) Increased garlic in the food
(c) Drink hot water
(d) Avoid eating from outside
(e) No change

\section{Mean score $\pm \mathrm{SD}$, (range)}

P9 Do you take herbal products and traditional medicines to prevent contracting and spreading of COVID-19?

$$
\begin{aligned}
& \text { Yes } \\
& \text { No } \\
& \text { Do not know }
\end{aligned}
$$$$
2.4 \pm 1.5,(0-4)
$$

2

$1.9 \pm 0.3,(1-2)$

$\begin{array}{ll}1 & 98(49) \\ 1 & 72(36) \\ 1 & 116(58) \\ 1 & 150(75) \\ 0 & 4(2) \\ 2.18 \pm(0-4) & \\ 1 & 62(31) \\ 0 & 104(52) \\ 0 & 34(17) \\ 0.3 \pm 0.5,(0-1) & \\ 1 & 56(28) \\ 1 & 70(35) \\ 1 & 54(27) \\ 0 & 20(10) \\ 0.9 \pm 0.3,(0-1) & \\ 2 & 76(38) \\ 1 & 38(19) \\ 1 & 86(43) \\ 1.4 \pm 0.5,(1-2) & \\ 15.5 \pm 2.6,(9-21) & \end{array}$

*Due to multiple responses, more than $100 \%$ is possible 
Table 5 Comparison of baseline characteristics of study participants and mean knowledge and practice score using ANOVA or $t$-test

\begin{tabular}{|c|c|c|c|c|c|c|}
\hline \multirow[t]{2}{*}{ Parameter } & \multicolumn{3}{|c|}{ Knowledge score } & \multicolumn{3}{|c|}{ Practice score } \\
\hline & Mean & SD & $P$-value ${ }^{\mathrm{a}}$ & Mean & SD & $P$-value ${ }^{\text {a }}$ \\
\hline Overall & 22.5 & 3.5 & & 15.5 & 2.652 & \\
\hline \multicolumn{7}{|l|}{ Education } \\
\hline Till primary level & 21.5 & 4.5 & 0.108 & 15.0 & 2.6 & 0.370 \\
\hline Secondary level & 23.0 & 2.6 & & 15.4 & 2.7 & \\
\hline Graduation and above & 22.3 & 3.9 & & 15.8 & 2.5 & \\
\hline \multicolumn{7}{|l|}{ Occupation } \\
\hline Health care workers & 23.8 & 3.4 & $\mathbf{0 . 0 3 0}$ & 15.3 & 2.9 & 0.730 \\
\hline Non-health care workers & 22.3 & 3.5 & & 15.5 & 2.6 & \\
\hline \multicolumn{7}{|c|}{ Area of distribution by COVID-19 condition } \\
\hline Hotspot & 23.1 & 1.9 & 0.409 & 14.90 & 2.9 & 0.291 \\
\hline Non-hotspot & 22.4 & 3.7 & & 15.56 & 2.6 & \\
\hline
\end{tabular}

Bold value indicate statistically significant as $P$-value $<0.05$

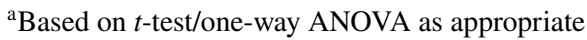

Table 6 Pearson's correlation between the study variable and different domains of knowledge and practices

\begin{tabular}{lcr}
\hline Variables $^{\mathrm{a}}$ & Correlation $(\Upsilon)$ & $P$-value \\
\hline $\begin{array}{l}\text { Overall knowledge versus } \\
\text { practice }\end{array}$ & 0.038 & 0.590 \\
K2 versus P2 & 0.150 & $0.034^{\mathrm{b}}$ \\
K2 versus P1 & 0.256 & $<0.001^{\mathrm{c}}$ \\
K3 versus P2 & 0.227 & $0.001^{\mathrm{c}}$ \\
K4 versus P1 & 0.205 & $0.004^{\mathrm{b}}$ \\
K8 versus P2 & 0.183 & $0.009^{\mathrm{b}}$ \\
K6 versus P9 & -0.162 & $0.022^{\mathrm{b}}$ \\
K9 versus P7 & 0.141 & $0.046^{\mathrm{b}}$ \\
\hline
\end{tabular}

${ }^{\mathrm{a}} \mathrm{K} 2$ : What type of disease is COVID-19?

$\mathrm{K} 3$ : Which group is at the highest risk of contracting severe form of COVID-19?

K4: Which of the following are symptoms suggestive of COVID-19?

K6: Which of the following are preventive measures for COVID-19?

K8: What is the trend of prevalence of COVID-19 in India?

K9: Does COVID-19 pose additional risk of infection to the pregnancy?

P1: What precautions are you practicing in order to prevent contracting and spreading of COVID-19?

P2: Has there been any change in the frequency of handwashing to prevent contracting and spreading of COVID-19?

P7: Do you wear a mask when you go outside your home to prevent contracting and spreading of COVID-19?

P9: Do you take herbal products and traditional medicines to prevent contracting and spreading of COVID-19?

${ }^{\mathrm{b}}$ Significant at $P<0.05$; ${ }^{\mathrm{c}}$ Highly significant at $P<0.001$

[15]. Around half (47\%) of the participants believed that formula feed was the feeding option of choice for COVID-19 positive mothers followed by expressed breast milk (25\%) and direct breastfeeding (17\%) while $23 \%$ participants did not answer. Also, mode of delivery was another less known area among the respondents as only $23 \%$ correctly answered that there was no effect on the method of delivery. These are potential areas for health education programmes and mass media coverage for reducing the gap of knowledge among pregnant women in order to enhance their attitude and practices.

Overall, the respondents showed positive attitude regarding seriousness for following preventive measures against COVID-19 (96\%) and visiting health care facility when suspected to have COVID-19 related symptoms (86\%). 86\% pregnant women believed that India could emerge victorious in the fight against this health emergency. These findings are in line with recent studies by Zhong et al. and Al-Hanawi et al. where the results showed positive attitude among general public $[9,16]$. Positive attitude and confidence in control of COVID-19 among pregnant mothers could be a reflection of the government's relentless actions, stringent steps such as nationwide lockdown and suspension of routine activities such as schools and universities, domestic and international flights [4].

It is a common consensus that more educated people comply better with preventive and treatment measures but there was no significant statistical correlation ( $p$-value 0.590 ) in this study between overall knowledge score and the practices followed. Participants (64\%) were overall following good practices (mean score $=15.5$, median score $=15$ ) for prevention of COVID-19 infection. This could be due to constant reinforcements by GOI through mass media coverage regarding good practices for prevention such as social distancing, wearing masks and hand hygiene [4]. Around $87 \%$ of pregnant women reported increased frequency of handwashing during COVID-19 pandemic and it was significantly increased $(r=0.150, P$-value 0.034$)$ among those who were aware about communicable nature of the disease. 
Also, this group of pregnant women frequently practiced increased safety measures such as wearing masks (98\%), avoiding crowded places (95\%), avoiding handshakes (91\%), social distancing (89\%) and washing vegetables before storing them (89\%) which could be explained by their awareness of mode of spread of disease. It is similar to level of practice observed in the study among pregnant women by Kamal et al. [10]. These preventive measures were followed more by those who had good knowledge about common symptoms of COVID-19 ( $r$-0.205, $P$-value 0.004). Also, awareness about increasing trend of COVID-19 in India had a significant increased impact $(r-0.183, P$-value 0.009$)$ on the frequency of handwashing. Awareness about effective preventive measures for COVID-19 had significantly negative impact on use of herbal or traditional medicines among participants. This could also be explained as a practice of avoiding unnecessary herbs/traditional medicines during pregnancy owing to possible adverse effects of these on foetus [17].

This study results could help the authorities in formulating policies directed towards the pregnant women with a special focus on those with low KAP (example-non-health care workers) who are at higher risk of contracting the disease. The areas that need to be focussed possibly include duration of handwashing and preferred method of breastfeeding in COVID-19 mother. Pregnancy is a landmark requiring extra attention and dissemination of information regarding knowledge and right practices will help diminish the anxiety and apprehension among the pregnant women and their relatives and will enhance positive attitude.

To the best of our knowledge, this is one of the initial studies providing insight into KAP among pregnant women in India. The questionnaire had been designed based on standard RCOG guideline and WHO resources and it evaluated various aspects of COVID-19 disease. This study was specific to pregnant population and hence, data might be helpful in formulating health policies targeting this subpopulation. Also, good knowledge, right practices and positive attitude are the only pillars of prevention with novel coronavirus variants, rising number of cases and uncertain future [18]. Due to evolving evidence on this topic, answers to the questionnaire may change with time. Furthermore, it is a single centre study and may not be generalised to the entire population. In future, multicentric research is warranted for better KAP assessment of pregnant women.

\section{Conclusion}

This study demonstrated that majority of the pregnant women had satisfactory knowledge, positive attitude and were following appropriate practices regarding COVID-19 but further efforts in creating awareness should be continued.
Knowledge on handwashing and breastfeeding in COVID-19 positive mothers was significantly low in pregnant women. As India is battling the second coronavirus wave and in the absence of definitive cure, strengthening of health policies directed at pregnant women should be prioritized with special focus on significant gaps in KAP.

\section{Declarations}

Conflict of interest The authors declare that they have no conflict of interest.

Consent for participation Informed consent was obtained from all individual participants included in the study.

Consent for publication Obtained.

Ethical approval Ethical clearance was obtained from the Institute Ethics Committee for Post Graduate Research (IECPG-247/24.06.2020, RT-32/22.07.2020). All procedures performed in studies involving human participants were in accordance with the 1964 Helsinki declaration and its later amendments or comparable ethical standards. The study protocol was approved by the Institute Ethics Committee, All India Institute of Medical Sciences, New Delhi.

Human or Animal Rights This article does not contain any studies with human participants or animals performed by any of the authors.

Informed Consent All participants gave written informed consent before the study began.

\section{References}

1. Chen H, Guo J, Wang C, et al. Clinical characteristics and intrauterine vertical transmission potential of COVID-19 infection in nine pregnant women: a retrospective review of medical records. Lancet. 2020;395(10226):809-15.

2. Andrews MA, Areekal B, Rajesh KR, Krishnan J, Suryakala R, Krishnan B, Muraly CP, Santhosh PV. First confirmed case of COVID-19 infection in India: a case report. Indian J Med Res. 2020;151(5):490-2.

3. Docherty AB, Harrison EM, Green CA, et al. Features of 20133 UK patients in hospital with covid-19 using the ISARIC WHO Clinical Characterisation Protocol: prospective observational cohort study. BMJ. 2020; 369:m1985.

4. National Portal of India. Combating Coronavirus [NPI website]. https://www.india.gov.in/spotlight/combating-coronavirus [Accessed January 17, 2021].

5. Abe K, Hamada H, Yamada T, et al. Impact of planning of pregnancy in women with epilepsy on seizure control during pregnancy and on maternal and neonatal outcomes. Seizure. 2014;23:112-1166.

6. McCauley M, Minsky S, Viswanath K. The H1N1 pandemic: media frames, stigmatization and coping. BMC Public Health. 2013;3(13):1116.

7. World Health Organization. Advice for the public on COVID19 (WHO website). https://www.who.int/emergencies/diseases/ novel-coronavirus-2019/advice-for-public. Accessed January 17, 2021. 
8. World Health Organization. Coronavirus disease (COVID-19): Pregnancy and childbirth [WHO website]. https://www.who.int/ news-room/q-a-detail/coronavirus-disease-covid-19-pregnancyand-childbirth [Accessed April 30, 2021].

9. Zhong BL, Luo W, Li HM, et al. Knowledge, attitudes, and practices towards COVID-19 among Chinese residents during the rapid rise period of the COVID-19 outbreak: a quick online crosssectional survey. Int J Biol Sci. 2020;16(10):1745-52.

10. Kamal D, Thakur VD, Swain SK, et al. Knowledge, attitude, and practice toward COVID-19 among pregnant women in a tertiary care hospital during the COVID-19 outbreak. J Mar Med Soc. 2020;22(Suppl S1):66-71.

11. Nwafor JI, Aniukwu JK, Anozie BO, et al. Pregnant women's knowledge and practice of preventive measures against COVID19 in a low-resource African setting. Int J Gynaecol Obstet. 2020;150(1):121-3.

12. Erfani A, Shahriarirad R, Ranjbar K, et al. Knowledge, attitude and practice toward the novel coronavirus (COVID-19) outbreak: a population-based survey in Iran. Bull World Health Organ. 2020; 30(10.2471).

13. Huang Y, Zhao N. Generalized anxiety disorder, depressive symptoms and sleep quality during COVID-19 outbreak in China: a web-based cross-sectional survey. Psychiatry Res. 2020;288:112954.

14. Durankuş F, Aksu E. Effects of the COVID-19 pandemic on anxiety and depressive symptoms in pregnant women: a preliminary study. J Matern Fetal Neonatal Med. 2020;18:1-7.

15. World Health Organization. COVID-19 vaccines [WHO website]. https://www. who.int/emergencies/diseases/novel-coronavirus2019/covid-19-vaccines [Accessed January 4, 2021].

16. Al-Hanawi MK, Angawi K, Alshareef N, et al. Knowledge, attitude and practice toward COVID-19 among the public in the
Kingdom of Saudi Arabia: a cross-sectional study. Front Public Health. 2020;27(8):217.

17. John LJ, Shantakumari N. Herbal medicines use during pregnancy: a review from the Middle East. Oman Med J. 2015;30(4):229-36.

18. World Health Organization. India Situation Report [WHO website]. https://www.who.int/india/emergencies/coronavirus-disea se-(covid-19)/india-situation-report [Accessed April 15, 2021].

Publisher's Note Springer Nature remains neutral with regard to jurisdictional claims in published maps and institutional affiliations.

\section{About the Author}

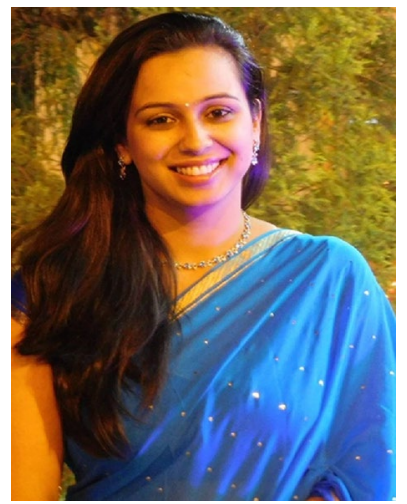

Anubhuti Rana is working as an Assistant Professor in the Department of Obstetrics and Gynaecology, AIIMS, New Delhi. She is a recipient of various best paper/poster awards at national conferences. She has many indexed scientific publications and chapters in books. She has special interest in Maternal Fetal Medicine and quality improvement projects.

\section{Authors and Affiliations}

\section{Tarang P. Kaur ${ }^{1} \cdot$ Anubhuti Rana $^{1}$ (D) . Vanamail Perumal ${ }^{1} \cdot$ Aparna Sharma $^{1} \cdot$ Vatsla Dadhwal $^{1} \cdot$ Vidushi Kulshrestha $^{1}$. Seema Singhal ${ }^{1} \cdot$ Jyoti Meena ${ }^{1} \cdot$ Sunesh Kumar ${ }^{1} \cdot$ Neerja Bhatla ${ }^{1}$}

Anubhuti Rana

anubhuti_rana@yahoo.com
1 Department of Obstetrics and Gynaecology, All India Institute of Medical Sciences, New Delhi, India 